Earth Interactions - Volume 22 (2018) • Paper No. 8 • Page 1

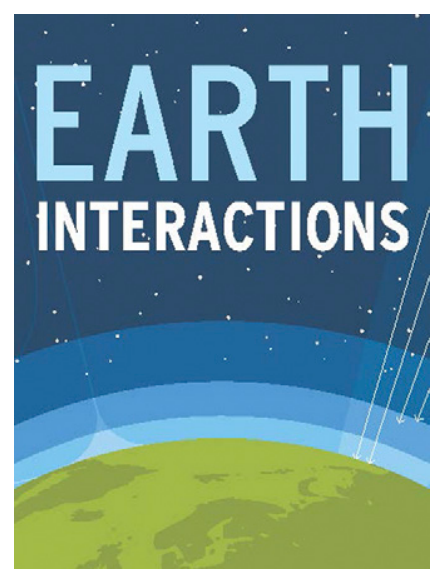

(C) 2018 American Meteorological Society. For information regarding reuse of this content and general copyright information, consult the AMS Copyright Policy (www.ametsoc.org/PUBSReuseLicenses).

\title{
Nonuniform Time-Lag Effects of Asymmetric Warming on Net Primary Productivity across Global Terrestriall Biomes
}

\section{Youyue Wen, Xiaoping Liu, ${ }^{\text {a }}$ and Guoming Du}

School of Geography and Planning, Sun Yat-sen University, Guangzhou, China

Received 14 November 2017; in final form 5 February 2018

\begin{abstract}
Climate warming exhibits asymmetric patterns over a diel time, with the trend of nighttime warming exceeding that of daytime warming, a phenomenon commonly known as asymmetric warming. Recently, increasing studies have documented the significant instantaneous impacts of asymmetric warming on terrestrial vegetation growth, but the indirect effects of asymmetric warming carrying over vegetation growth (referred to here as time-lag effects) remain unknown. Here, we quantitatively studied the time-lag effects (within 1 year) of asymmetric warming on global plant biomes by using terrestrial vegetation net primary production (NPP) derived by the Carnegie-Ames-Stanford Approach (CASA) model and accumulated daytime and nighttime temperature (ATmax and ATmin) from 1982 to 2013. Partial correlation and time-lag analyses were conducted at a monthly scale to obtain the partial correlation coefficients between NPP and ATmax/ATmin and the lagged durations of NPP responses to ATmax/ATmin. The results showed that (i) asymmetric warming has nonuniform time-lag effects on single plant biomes, and distinguishing correlations exist in different vegetation biomes' associations to asymmetric
\end{abstract}

${ }^{a}$ Corresponding author: Xiaoping Liu, liuxp3@mail.sysu.edu.cn

DOI: 10.1175/EI-D-17-0032.1 
Earth Interactions - Volume 22 (2018) - Paper No. 8 - Page 2

warming; (ii) terrestrial biomes respond to ATmax (4.63 \pm 3.92 months) with a shorter protracted duration than to ATmin (6.06 \pm 4.27 months); (iii) forest biomes exhibit longer prolonged duration in responding to asymmetric warming than nonforest biomes do; (iv) mosses and lichens (Mosses), evergreen needleleaf forests (ENF), deciduous needleleaf forests (DNF), and mixed forests (MF) tend to positively correlate with ATmax, whereas the other biomes associate with ATmax with near-equal splits of positive and negative correlation; and (v) ATmin has a predominantly positive influence on terrestrial biomes, except for Mosses and DNF. This study provides a new perspective on terrestrial ecosystem responses to asymmetric warming and highlights the importance of including such nonuniform time-lag effects into currently used terrestrial ecosystem models during future investigations of vegetation-climate interactions.

KEYWORDS: Vegetation-atmosphere interactions; Climate prediction; Climate variability

\section{Introduction}

Terrestrial net primary production (NPP) is the rate of net organic biomass accumulation by plants per unit area and time (Potter et al. 1999). It serves as a crucial component in the global carbon cycle. Variations in NPP reflect the vegetation changes in terrestrial ecosystems, which integrate multiple environmental changes from both nature and anthropogenic influences (Nemani et al. 2003; Potter et al. 1999). The terrestrial NPP is sensitive to climate change (Gang et al. 2013; Li et al. 2015; Potter et al. 2012; Su et al. 2015; Zhao et al. 2015), and the interactions between climate change and NPP have been a hot topic. The climate condition is ever changing over a given period of time, during which time the climate may form different impacts on vegetation growth, referred to here as antecedent climate effects; however, there is still a lack of knowledge regarding how antecedent climate affects present vegetation productivities.

Previous studies have provided credible evidence that there is a generally greater tendency toward an increase in the daily minimum temperature than in the daily maximum temperature, which exhibits not only spatial nonuniformities (Caesar et al. 2006; Easterling et al. 1997; IPCC 2014), but also temporal heterogeneities (Caesar et al. 2006; Matiu et al. 2016; van Wijngaarden and Mouraviev 2016). These phenomena are often referred to as asymmetric warming (Peng et al. 2013; Phillips et al. 2016; Su et al. 2015), which can be defined as the phenomenon of spatiotemporally nonuniform warming tendencies in day- versus nighttime temperatures.

Currently, increasing studies have revealed the significant effects of asymmetric warming on terrestrial ecosystem carbon budgets. For example, Su et al. (2015) reported that terrestrial NPP is significantly higher under asymmetric warming than symmetric warming scenarios; Tan et al. (2015) and Xia et al. (2014) found that the asymmetry in climate warming has nonuniform effects on the Northern Hemisphere terrestrial carbon cycling, and these uniform effects vary by regions and seasons; and Anderegg et al. (2015) further showed that nocturnal warming dominates the carbon losses of a tropical climate through enhanced dark respiration. Apart from these model-based studies, there still exist many in situ studies. For example, Wan et al. (2009) revealed that the nocturnal-warming-derived carbon losses in the temperate steppe ecosystem can be compensated by stimulating the following daytime photosynthesis through the depletions of leaf carbohydrates in grassland (Grass) at night; Xie et al. (2014) revealed that the increases in the aboveground biomass of rice will 
Earth Interactions - Volume 22 (2018) • Paper No. 8 • Page 3

be significantly enhanced by asymmetric warming in the jointing stage, but suppressed in the maturity stage; and Phillips et al. (2016) suggested that this warming asymmetry would turn the grassland ecosystems into a carbon source, mainly by enhancing the warming-induced carbon losses from unprotected soil.

These aforementioned experiments acknowledged the significant effects of asymmetric warming on terrestrial vegetation, but they mostly focused on the simultaneous impacts of asymmetric warming and did not consider the time-lag effects that the antecedent asymmetric warming may have had on vegetation growth (Braswell et al. 1997; Potter et al. 1999; Wu et al. 2015; Xia et al. 2014). The time-lag effect is defined as the indirect impact of an antecedent climate factor (specifically referring to asymmetric warming in this study) on present vegetation growth, which takes a period of time to actually occur. There are two important aspects in the time-lag effect: one is the lagged duration that one climate factor may have on the vegetation growth, and the other is the correlation between them at this specific lagged duration.

Determining the time-lag effects of asymmetric warming on terrestrial vegetation growth and ascertaining the underlying mechanisms has many levels of meaning (Braswell et al. 1997; Wu et al. 2015): first, it helps enrich the knowledge of the climate-vegetation science, and second, it benefits environmental management because policy-makers can provide future warnings about the possible changes in the terrestrial ecosystem resulting from the anomalous temperature fluctuations. Increasing bodies of evidence have shown the common existence of significant timelag effects of climate factors on vegetation growth (Braswell et al. 1997; Kuzyakov and Gavrichkova 2010; Sherry et al. 2008; Wu et al. 2015; Zhang et al. 2015; Zhao et al. 2015). The asymmetric warming is projected to be reinforced (IPCC 2014), which is anticipated to generate enormous effects on the terrestrial green plants' growth (Matiu et al. 2016; Peng et al. 2013; Su et al. 2015; Xie et al. 2014). However, little is known about the time-lag effects that asymmetric warming have on different plant biomes. Therefore, it is both urgent and important to determine the time-lag effects of antecedent asymmetric warming on the terrestrial plant biomes.

In this study, we hypothesized that nonuniform time-lag effects exist in the responses of the same types of vegetation biome to day- versus nighttime warming and that distinguished time-lag effects are exhibited in the vegetation responses to asymmetric warming across different biomes. With regards to these hypotheses, we tried to address the following goals:

1) quantifying the lagged durations of terrestrial plant biomes when responding to asymmetric warming and

2) determining the correlations between different plant biomes and asymmetric warming with time-lag effects considered.

\section{Materials and methods}

\subsection{Global datasets}

\subsubsection{GIMMS NDVI dataset}

The Normalized Difference Vegetation Index (NDVI) is a widely used proxy of terrestrial NPP (Nemani et al. 2003; Potter et al. 2012; Zhao et al. 2015). The 
Earth Interactions - Volume 22 (2018) • Paper No. 8 • Page 4

Global Inventory Monitoring and Modeling Studies (GIMMS) group produced a continuously updated global NDVI dataset (GIMMS NDVI) (Tucker et al. 2005); the third-generation GIMMS NDVI (first version, NDVI.3g.v1) is now available from July 1981 to December 2015. NDVI.3g.v1 is a new time series dataset with the most inaccuracies (e.g., the orbital drift artifacts, sensor degradation, and cloud contamination) optimally removed. NDVI.3g.v1 possesses a spatial resolution of $1 / 12^{\circ}$ and a biweekly interval (Tucker et al. 2005). The GIMMS NDVI exhibits limitationsregional disagreements in NDVI-derived trends when compared to other satellite NDVI products (Fensholt and Proud 2012; Song et al. 2010) and discrepancies in reflecting true vegetation changes in some ecosystems (i.e., the Arctic zones and tropical regions; Fensholt and Proud 2012) — but the advantages of a long-term, hypertemporal record of continuous satellite data and the overall good correlations (Fensholt and Proud 2012; Song et al. 2010) and spatial characteristics with true vegetation phenological metrics (Atzberger et al. 2013) and biomass changes (Wang et al. 2014) make the GIMMS NDVI a well-acknowledged and widely applied data source in long-term vegetation-climate studies (Peng et al. 2013; Piao et al. 2015; Tan et al. 2015; Wu et al. 2015). To further minimize the residual atmospheric effects, we applied the maximum value composites (MVC) method (Holben 1986) to the biweekly composited NDVI to construct a monthly time series.

\subsubsection{Climatic datasets}

Monthly climate datasets with a $0.5^{\circ}$ resolution were taken from January 1982 to December 2013 in the present study. The monthly average, maximum, and minimum temperatures (TEM, Tmax, and Tmin, respectively) and the monthly total precipitation (PRCP) were all obtained from the Climatic Research Unit (CRU), version TS3.22 (Harris et al. 2014). The CRU TS3.22 is an updated gridded dataset covering the global land areas from $60^{\circ} \mathrm{S}$ to $80^{\circ} \mathrm{N}$, primarily derived from climate station records and interpolated into $0.5^{\circ} \times 0.5^{\circ}$ grids. Its earlier products were released prior to 2013, and additional corrections were made to previous versions of CRU TS3.21 (Harris et al. 2014). The monthly incoming shortwave solar radiation data (SOLAR) from Princeton Global Forcings, version 2, were provided by the Terrestrial Hydrology Research Group at Princeton University (Sheffield et al. 2006). The long-time meteorological forcing data are a combination of the National Centers for Environmental Prediction and the National Center for Atmospheric Research (NCEP-NCAR) reanalysis datasets, in which the known errors were carefully corrected by observation-based datasets (Sheffield et al. 2006), and these superiorities allow it to drive the land surface terrestrial model well (Troy and Wood 2009). The major weaknesses of these meteorological materials are their relatively coarse spatial resolution $\left(0.5^{\circ}\right)$ and temporal resolution (monthly) (Tanarhte et al. 2012; Zhang et al. 2013), but they have the strength of near-global coverage and are suitable for long-term climatic trend analyses (Harris et al. 2014; Sheffield et al. 2006), which makes them good candidates for detecting the global vegetation-climate interactions (Peng et al. 2013; Piao et al. 2015; Tan et al. 2015; Wu et al. 2015).

\subsubsection{Other datasets}

We primarily focused on the effects of asymmetric warming on vegetation growth; therefore, for the purpose of minimizing the effects from land-cover 


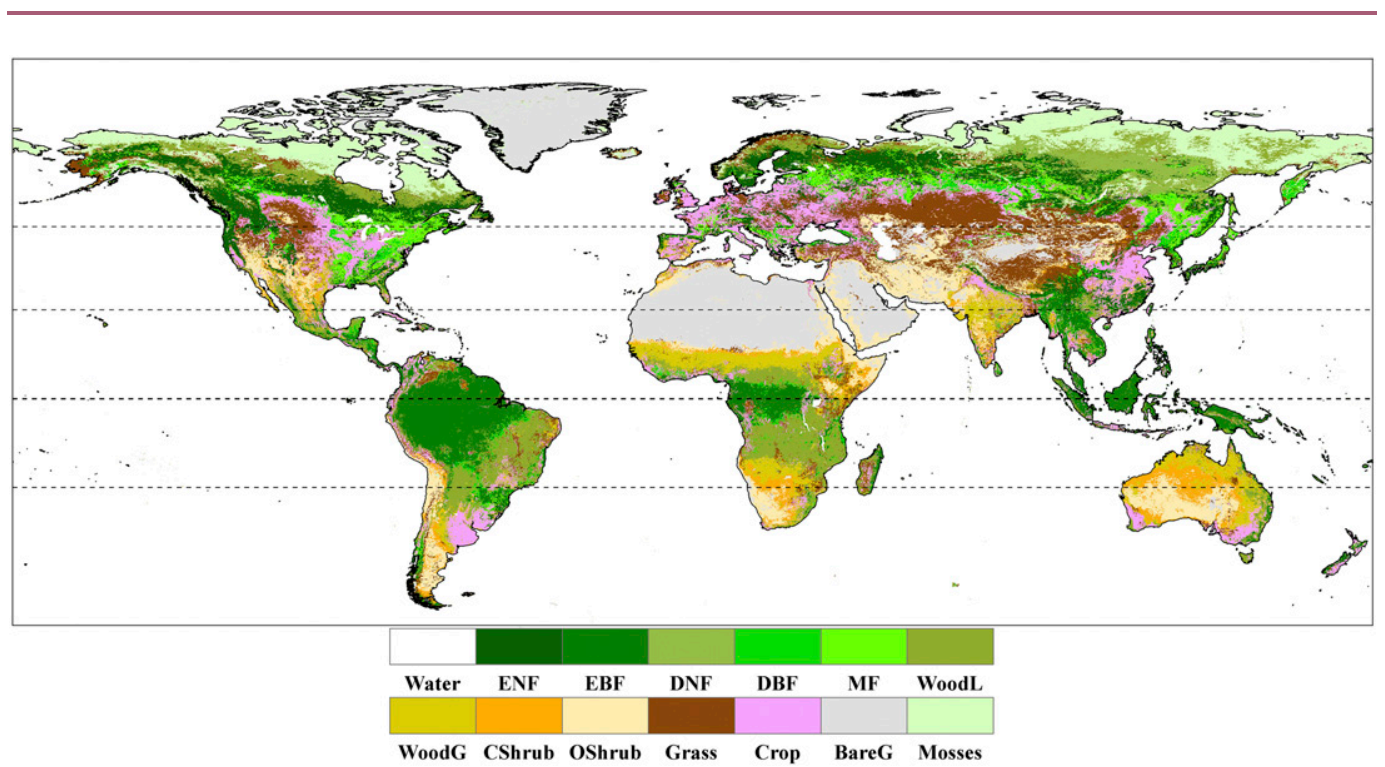

Figure 1. Global land-cover classification product from UMD_GVM. Vegetation biomes are introduced in Table 1.

changes and analyzing the special responses of each vegetation biome to asymmetric warming, we used the vegetation biomes obtained from the University of Maryland's Department of Geography (UMD_GVM) throughout this work. Applying decision tree classifiers, the UMD_GVM classifies 14 global biomes (Figure 1 and Table 1), with an overall accuracy between $81.4 \%$ and $90.3 \%$ (De Fries et al. 1998). It documented vegetation biomes numerically from 0 to 13 , in which 0 refers to water land (i.e., the oceans and lakes), 1-5 represent forest biomes, and 613 refer to nonforest biomes. The UMD_GVM has a spatial resolution of $\sim 8 \mathrm{~km}$ and has been well adopted in global-vegetation-monitoring studies (Nemani et al. 2003; Zhou et al. 2003). In addition, the global soil map originating from the Harmonized World Soil Database (HWSD v1.2; FAO et al. 2012) is used to obtain the global soil textures, which determine the soil water-holding ability and are an essential input for driving the Carnegie-Ames-Stanford Approach (CASA) model. Finally, the field NPP data from the revised Global Primary Production Data Initiative Products (GPPDI R2; Olson et al. 2013) were adopted to validate the NPP simulated by CASA. The GPPDI R2 covers 2525 individual sites and 5164 grid cells $\left(0.5^{\circ}\right)$, and each measurement of individual points and grids provides an annual NPP estimation $\left(\mathrm{gC} \mathrm{m}^{-2} \mathrm{yr}^{-1}\right)$ covering the period from 1931 to 1996. It is a well-acknowledged dataset for validating a global model-derived NPP estimation (Gang et al. 2015; Potter et al. 2012).

\subsection{Methods}

CASA model for this study, we first simulated the global terrestrial NPP through the CASA model to indicate the vegetation growth, and we calculated the accumulated monthly daytime and nighttime temperatures (ATmax and ATmin) to 
Earth Interactions • Volume 22 (2018) • Paper No. 8 • Page 6

Table 1. The list of vegetation biomes provided by UMD_GVM and their acronyms that were used in this study.

\begin{tabular}{rll}
\hline & UMD_GVM vegetation biomes & Acronym \\
\hline 1 & Evergreen needleleaf forest & ENF \\
2 & Evergreen broadleaf forest & EBF \\
3 & Deciduous needleleaf forest & DNF \\
4 & Deciduous broadleaf forest & DBF \\
5 & Mixed forest & MF \\
6 & Woodland & WoodL \\
7 & Wooded grassland & WoodG \\
8 & Closed shrubland & CShrub \\
9 & Open shrubland & OShrub \\
10 & Grassland & Grass \\
11 & Cropland & Crop \\
12 & Bare ground & BareG \\
13 & Mosses and lichens & Mosses \\
\hline
\end{tabular}

reflect the asymmetric warming condition. The partial correlation and time-lag analyses were then conducted collectively on a monthly scale to obtain the partial correlation coefficients (PCC) between NPP and ATmax/ATmin and the lagged duration of NPP responses to ATmax/ATmin among different plant biomes. Finally, the frequency and magnitude of the lagged duration and PCC were further investigated within different vegetation biomes. It is worth mentioning that the statistical analyses in this study were based on the vegetation growing season, defined as the months when the monthly average temperature was higher than $0^{\circ} \mathrm{C}$, and NDVI was higher than 0.2 (Wu et al. 2015), so the correlation and the timelagged effects were specified to those of vegetation growth responses to ambient temperatures during the growing season.

\subsubsection{NPP estimation}

The CASA model is a light-use efficiency (LUE)-based model and was first developed by Potter et al. (1993). It can be driven by easily obtained datasets (i.e., TEM, PRCP, SOLAR, land covers, and soil properties) and has the advantage of being based on satellite data (NDVI), which makes it a good candidate for vast ecosystem productivity simulations. In detail, CASA computes NPP using the following formula:

$$
\mathrm{NPP}=0.5 \times \mathrm{SOLAR} \times \mathrm{FPAR} \times T_{1} \times T_{2} \times W_{s} \times \varepsilon_{\max } .
$$

The fraction of photosynthetically active radiation (FPAR) absorbed by vegetation is a function of NDVI, $T_{1}$ denotes the limitation of extreme low and high temperatures on LUE, and $T_{2}$ reflects the LUE when the temperature rises above or falls below the optimum temperature $\left({ }^{\circ} \mathrm{C}\right)$ when the NDVI reaches its maximum values throughout the year; $T_{1}$ and $T_{2}$ are regulated by TEM and the optimum temperature. $W_{s}$ is moisture pressure on vegetation growth and is a function of TEM and PRCP, and $\varepsilon_{\max }\left(\mathrm{gC} \cdot \mathrm{MJ}^{-1}\right)$ is the maximum light-use efficiency for plants under optimal living conditions. The detailed calculation steps for each parameter strictly followed the descriptions documented by Potter et al. (1993). 
Earth Interactions - Volume 22 (2018) $\quad$ - Paper No. 8 • Page 7

\subsubsection{Calculation of accumulated temperature}

Most previous studies (Braswell et al. 1997; Musau et al. 2016; Sherry et al. 2008; Wu et al. 2015) only included a point on a time scale, rather than a time range, when investigating the time-lag effects of antecedent temperature on present plant growth. That is, suppose the air temperature has a time-lag effect of 2 months on the vegetation growth in the present month: these studies only studied the associations between the condition of temperature of 2 months ago and the vegetation status in the present month, without considering the climate conditions of the previous month and 1 month ago, which may also have significant impacts on the vegetation variations in the present month. Consequently, these studies ignored the important fact that the present growth and development of plants tend to be affected by a time range of antecedent temperatures (Peng et al. 2010; Zeng et al. 2013). This problem was managed by calculating the accumulated temperature in this study (Zeng et al. 2013).

Accumulated temperature is the temperature surplus with respect to a given base temperature $\left(T_{\text {base }}\right)$ and is accumulated over a period of time (i.e., month, season, or year). The accumulated temperature can indicate the thermal requirement for plant growth over a period of time, and it closely relates to the life-stage transitions of plants and contributes to the determination of the spatial distribution and productivity of green plants (Garcia-Mozo et al. 2000; Wang et al. 2013). Here, we computed the accumulated monthly Tmax (ATmax) and Tmin (ATmin) as Equations (2) and (3), respectively. It is noteworthy that the accumulated temperatures make no sense until the $T_{\text {base }}$ is specified; as it is considered the best temperature factor for predicting plant development over vast regions (Garcia-Mozo et al. 2000; Piao et al. 2015), $0^{\circ} \mathrm{C}$ is chosen as $T_{\text {base }}$. In addition, the accumulation period is defined as the supposed time-lag duration that antecedent asymmetric warming may have on vegetation growth. The longest time-lag duration is defined as 12 months, as previous studies showed that vegetation commonly undergoes time-lag effects within 1 year of the ambient environment (Sherry et al. 2008; Zhang et al. 2015):

$$
\begin{aligned}
& \operatorname{ATmax}(m, i)=\sum_{k=0}^{k=i}\left[\operatorname{Tmax}(m-k)-T_{\text {base }}\right](0 \leq k \leq i \leq 12), \\
& \operatorname{ATmin}(m, i)=\sum_{k=0}^{k=i}\left[\operatorname{Tmin}(m-k)-T_{\text {base }}\right](0 \leq k \leq i \leq 12),
\end{aligned}
$$

where $m$ is the month-year series from January 1982 to December 2013, $i$ is the supposed protracted duration, $k$ is the scale of the month prior to the present month $m$, and $T_{\text {base }}$ equals $0^{\circ} \mathrm{C}$. Note that following Garcia-Mozo et al. (2000)'s study, we assumed there is no addition to the ATmax or ATmin when Tmax or Tmin dropped below $T_{\text {base }}$; therefore, the ATmax and ATmin are always positive.

\subsubsection{Partial correlation analyses}

Partial correlation analysis is a favorable measurement for studying the associations between two factors $(X, Y)$ while eliminating the effects of a list of interferential variables $\left(Z=\left[Z_{1}, Z_{2} \ldots, Z_{n}\right]\right)$. This approach has been effectively employed when detecting the correlations between vegetation growth and a single 
climate element (Peng et al. 2013; Wu et al. 2015). In this study, we applied this method to obtain the associations between ATmax and NPP while controlling the variables of ATmin, SOLAR, and PRCP; likewise, we obtained the associations between ATmin and NPP while controlling the variables of ATmax, SOLAR, and PRCP (Peng et al. 2013). The PCC can be described as the following formula:

$$
R_{X Y \cdot Z}=\frac{R_{X Y}-R_{X Z} \times R_{Y Z}}{\sqrt{\left(1-R_{X Z}^{2}\right) \times\left(1-R_{Y Z}^{2}\right)}},
$$

where $R_{X Y \cdot Z}$ refers to the PCC between $X$ and $Y$ after controlling a set of variables ( $Z=\left[Z_{1}, Z_{2} \ldots, Z_{n}\right]$ ), and $R_{X Y}, R_{Y Z}$, and $R_{X Z}$ refer to the simple correlation coefficients of $X, Y$, and $Z$. If we intend to acquire the association between ATmax and NPP, then $R_{X Y \cdot Z}$ is the PCC between these two elements after excluding the influences from $Z=$ [ATmin, PRCP, SOLAR], and $R_{X Y}, R_{Y Z}$, and $R_{X Z}$ denote the ordinary correlations among variables ATmax (i.e., the independent variable of $X$ ), NPP (i.e., the dependent variable of $Y$ ), and $Z$. The PCC statistically ranges from -1 to 1 , where 1 is a fully positive correlation, 0 is no correlation, and -1 is a fully negative correlation.

\subsubsection{Analyses of time-lag effects}

Following previous studies (Braswell et al. 1997; Wu et al. 2015), we first obtained the corresponding PCC $\left(R_{0}, R_{2}, \ldots, R_{12}\right)$ between ATmax/ATmin and NPP at each supposed lagged duration. When the PCC $\left(\mathrm{R}_{\mathrm{k}} ; 0 \leq k \leq 12\right)$ reached its maximum determination coefficient $\left(R^{2}\right)$, that value was taken as the most favorable PCC $\left[R_{\text {best }}\right.$; Equation (5)] between ATmax/ATmin and NPP, and $k$ was considered the best time lag [BTL; Equation (6)] for NPP in relation to ATmax/ATmin:

$$
\begin{aligned}
& R_{\text {best }}=R_{k}, \quad \text { when } \quad R_{k}^{2}=\operatorname{Maximum}\left\{R_{1}^{2}, R_{2}^{2}, \ldots, R_{k}^{2} \ldots, R_{12}^{2}\right\}, \\
& \mathrm{BTL}=k, \quad \text { when } \quad R_{k}^{2}=\operatorname{Maximum}\left\{R_{1}^{2}, R_{2}^{2}, \ldots, R_{k}^{2} \ldots, R_{12}^{2}\right\} .
\end{aligned}
$$

\section{Results and analysis}

\subsection{Global predicted NPP and validation}

We compared the field-based NPP from the GPPDI R2 dataset with the 32-yr average annual NPP predicted by the CASA model (Figure 2). It can be seen from Figure 2 that strong similarities can be found between the measured and predicted NPPs for the "Natural Tall Vegetation" (Figure 3a; $R^{2}=0.77, p<0.001$ ) and the "Natural Short Vegetation" (Figure 3b; $R^{2}=0.69, p<0.001$ ), and moderate agreements can be found between the measured and simulated NPPs for the "Developed and Mosaic Lands" (Figure 3c; $R^{2}=0.51, p<0.001$ ) and "Others" (Figure $3 \mathrm{~d} ; R^{2}=0.45, p<0.001$ ). Combining all the samples of the vegetation classes, we got a result (Figure $3 \mathrm{e}$ ) with $R^{2}$ as high as $0.81(p<0.001)$. These results suggested our last predicted NPP is comparable to the observed NPP, though some errors still exist in our NPP estimate (as indicated by RMSE values). 
(a)

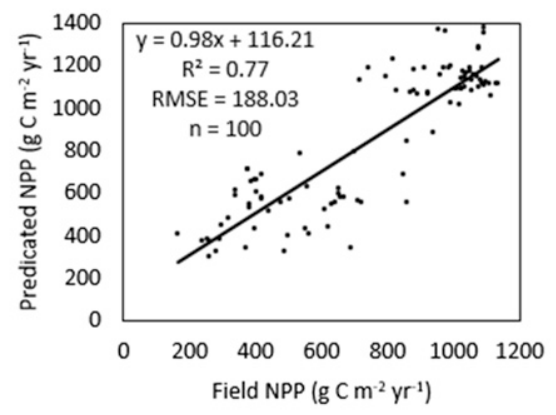

(c)

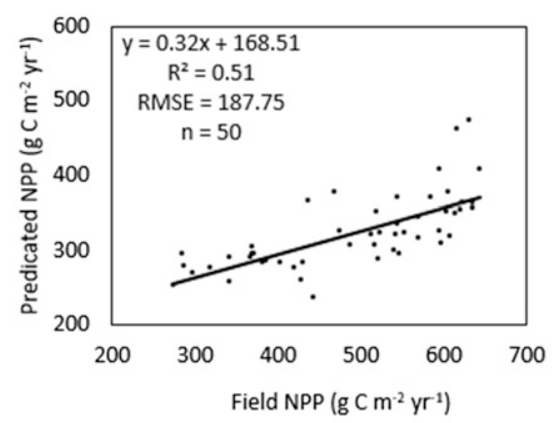

(e)

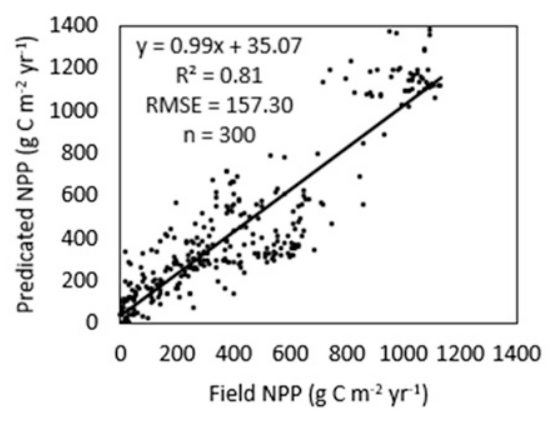

(b)

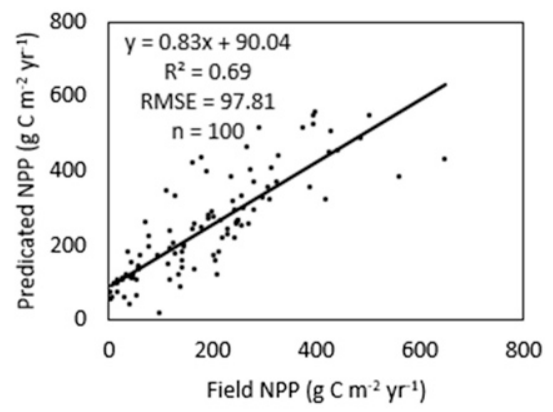

(d)

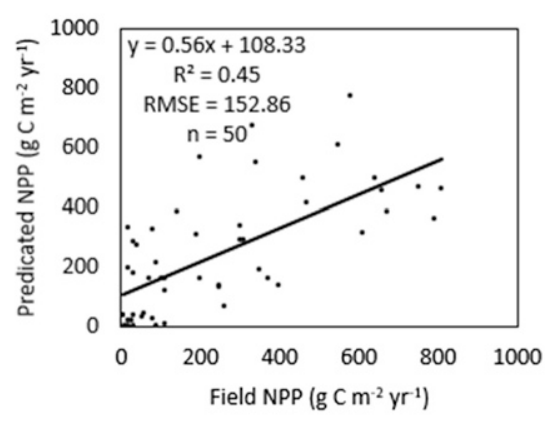

Figure 2. Comparison of observed and estimated NPP for the vegetation classes of (a) the "Natural Tall Vegetation" (height of vegetation exceeding $2 \mathrm{~m}$; includes ENF, EBF, DNF, DBF, MF and WoodL); (b) the "Natural Short Vegetation" (height of vegetation less than $2 \mathrm{~m}$; includes WoodG, Grass, CShrub and OShrub); (c) the "Developed and Mosaic Lands" (includes Crop), (d) "Others" (includes BareG and Mosses); and (e) all vegetation classes combined. These vegetation classes were reclassified following the study by Friedl et al. (2002). The vegetation biomes are introduced in Table 1. The field-based NPP originates from the GPPDI R2 dataset after removing the samples with missing data or undergone land-cover transformations, and predicated NPP is based on the average annual NPP values from 1982 to 2013 . We randomly obtained 300 samples to perform this validation, with 100 points for the Natural Tall Vegetation and for the Natural Short Vegetation, and 50 points for the Developed and Mosaic Lands and for Others. The $R^{2}$, RMSE, and $n$ represent determination coefficient, the root-mean-square error, and sample number in the comparisons between the field NPP and predicated NPP. 


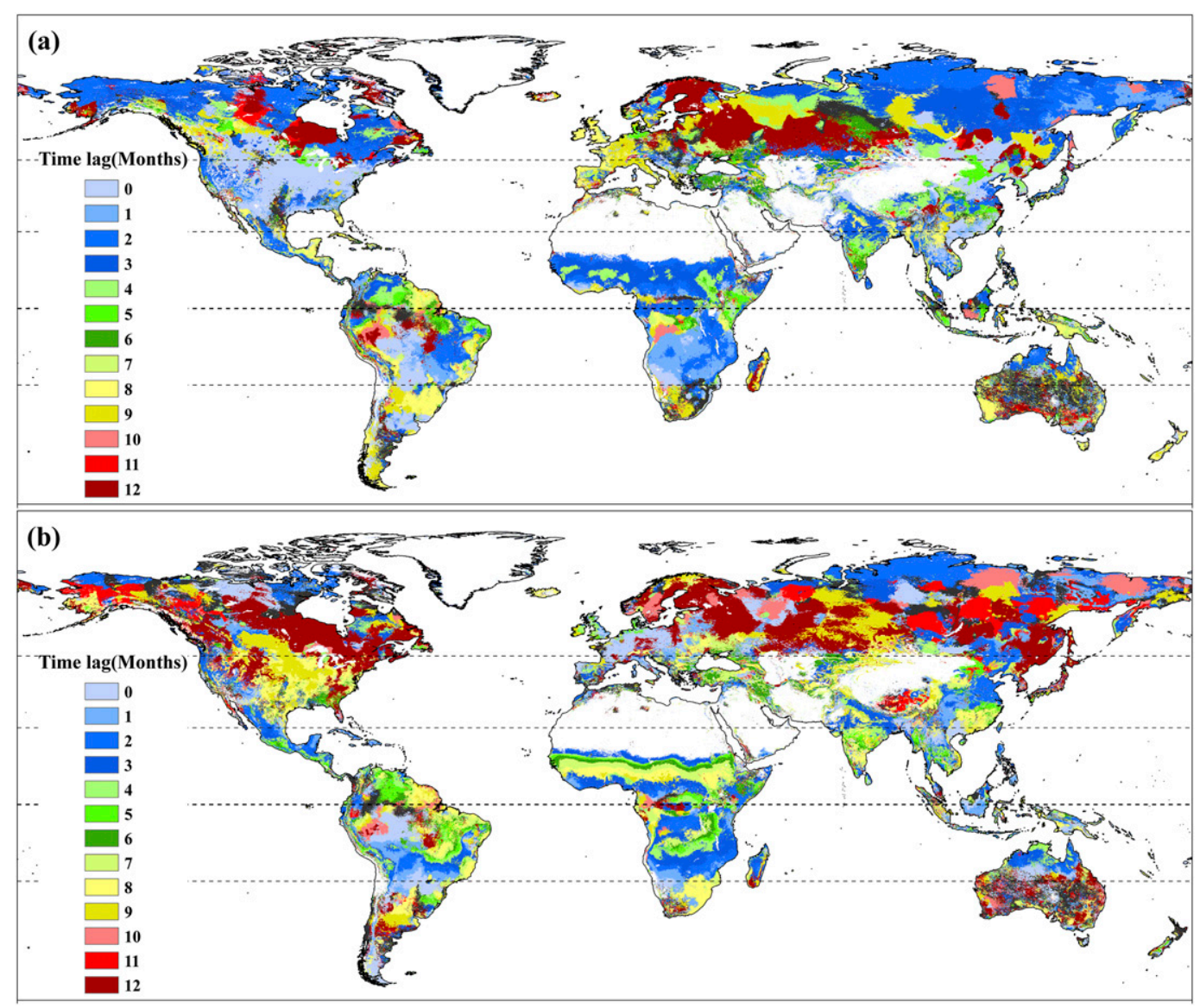

Figure 3. Spatial patterns of the BTLs for terrestrial NPP when responding to (a) ATmax and (b) ATmin for the period from 1982 to 2013. White areas refer to places with no data, and dark gray areas refer to places with no significant correlations.

Furthermore, we compared the global annual results of the model-estimated NPP in this study to those obtained in previous research (Table 2). Table 2 shows that the annual global NPP was estimated to be approximately 51.53 (49.48-54.08)

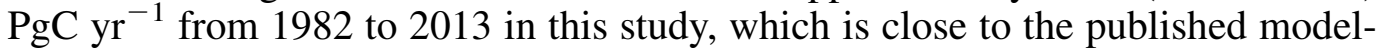
based results of some previous studies (Cramer et al. 1999; Li et al. 2015; Liao and

Table 2. Comparison of the model-estimated annual global NPP between this study and previous studies.

\begin{tabular}{lcll}
\hline Study period & NPP average/range $\left(\mathrm{PgC} \mathrm{yr}^{-1}\right)$ & \multicolumn{1}{c}{ Model } & \multicolumn{1}{c}{ References } \\
\hline 1986-2005 & $\mathbf{5 0 . 6}$ & 10 CMIP5 models & Li et al. (2015) \\
$1982-98$ & $(44.4-66.3)$ & 17 global models & Cramer et al. (1999) \\
$1982-99$ & $\mathbf{5 4 . 5 1}$ & GLO-PEM model & Nemani et al. (2003) \\
$2000-09$ & $\mathbf{5 3 . 5 2}(51.67-54.69)$ & MODIS NPP algorithm & Zhao and Running (2010) \\
$2002-10$ & $\mathbf{5 1 . 6}(54.9-49.9)$ & TEM model & Liao and Zhuang (2015) \\
$1982-2013$ & $\mathbf{5 1 . 5 3}(49.48-54.08)$ & CASA model & This study \\
\hline
\end{tabular}


Earth Interactions - Volume 22 (2018) • Paper No. 8 • Page 11

Table 3. Spatial correlation matrix among the plant biomes maps (Figure 1), lagged months of terrestrial NPP responding to ATmax (Figure 3a), and ATmin (Figure $3 \mathbf{b}$ ). These spatial correlations were obtained by using the ArcGIS geoprocessing toolBand Collection Statistics. A correlation matrix that indicates the correlation between the cell values from one raster layer to that from another can be yielded by using this tool. Correlation ranges from -1 to +1 , wherein the negative (positive) values indicate that the changes in the cell values of one layer inversely (directly) correlate to the other, and a correlation of zero means that two layers are independent of one another.

\begin{tabular}{lccc}
\hline & ATmax & ATmin & Vegetation biomes \\
\hline ATmax & 1 & 0.26 & -0.55 \\
ATmin & 0.26 & 1 & -0.65 \\
Vegetation biomes & -0.55 & -0.65 & 1 \\
\hline
\end{tabular}

Zhuang 2015; Nemani et al. 2003; Zhao et al. 2015). These validations suggest that our last predicted NPP is a credible result.

\subsection{Lagged duration of vegetation responses to asymmetric warming}

The spatial patterns of the BTL that the terrestrial NPP responds to ATmax (Figure 3a) and ATmin (Figure 3b) are shown in Figure 3. Overall, a lagged duration of $\sim 5$ months is exhibited in the responses of the NPP to both temperature elements, but ATmax (4.63 \pm 3.92 months) has a more immediate impact on the NPP than ATmin does (6.06 \pm 4.27 months). Most polar and boreal biomes respond to ATmax with a 2-to-3-month delay, but the green plants in northern cold-temperate regions tend to have lagged responses to ATmax that last for more than half a year; the green plants in warm-temperate and tropical regions, however, are inclined to respond to ATmax with instantaneous hysteretic impacts (0-3 months). Regarding the lagged time of ATmin on the NPP (Figure 3b), we found that the majority of vegetated pixels over northern cold and boreal zones $\left(45.5^{\circ}-65.5^{\circ} \mathrm{N}\right)$ were covered by lagged times of 9-12 months, and there are clear latitudinal gradients ( $0-9$ months) over the tropical regions (i.e., the Brazilian Plateau and Africa).

We compared the spatial correlations (Table 3) between the plant biomes map (Figure 1) and the lagged duration results (Figures 3a,b). According to Table 3, a narrow correlation $(R=0.26)$ is exhibited between Figure $3 \mathrm{a}$ and Figure $3 \mathrm{~b}$, indicating that high spatial heterogeneities are exhibited in the protracted duration of NPP responses to ATmax versus ATmin. Interestingly, there is a somewhat strong negative spatial correlation of Figure 1 to Figure $3 \mathrm{a}$ and Figure $3 \mathrm{~b}$, with $R=-0.55$ and $R=-0.65$, respectively. This result indicates that the hysteretic effects found in this study correspond well to vegetation biomes, and the negative $R$ values suggest that the larger the series number a biome has, the faster its response to asymmetric warming; that is, the forest biomes (number series of 1-5) tend to have longer lagged responses to asymmetric warming than nonforest biomes (number series of 6-13) do.

We further compared the frequency (Figure 4) and average (Figure 5) of BTLs among different vegetation biomes. It can be seen in Figure 4 that most of the grids 
Earth Interactions - Volume 22 (2018) - Paper No. 8 - Page 12
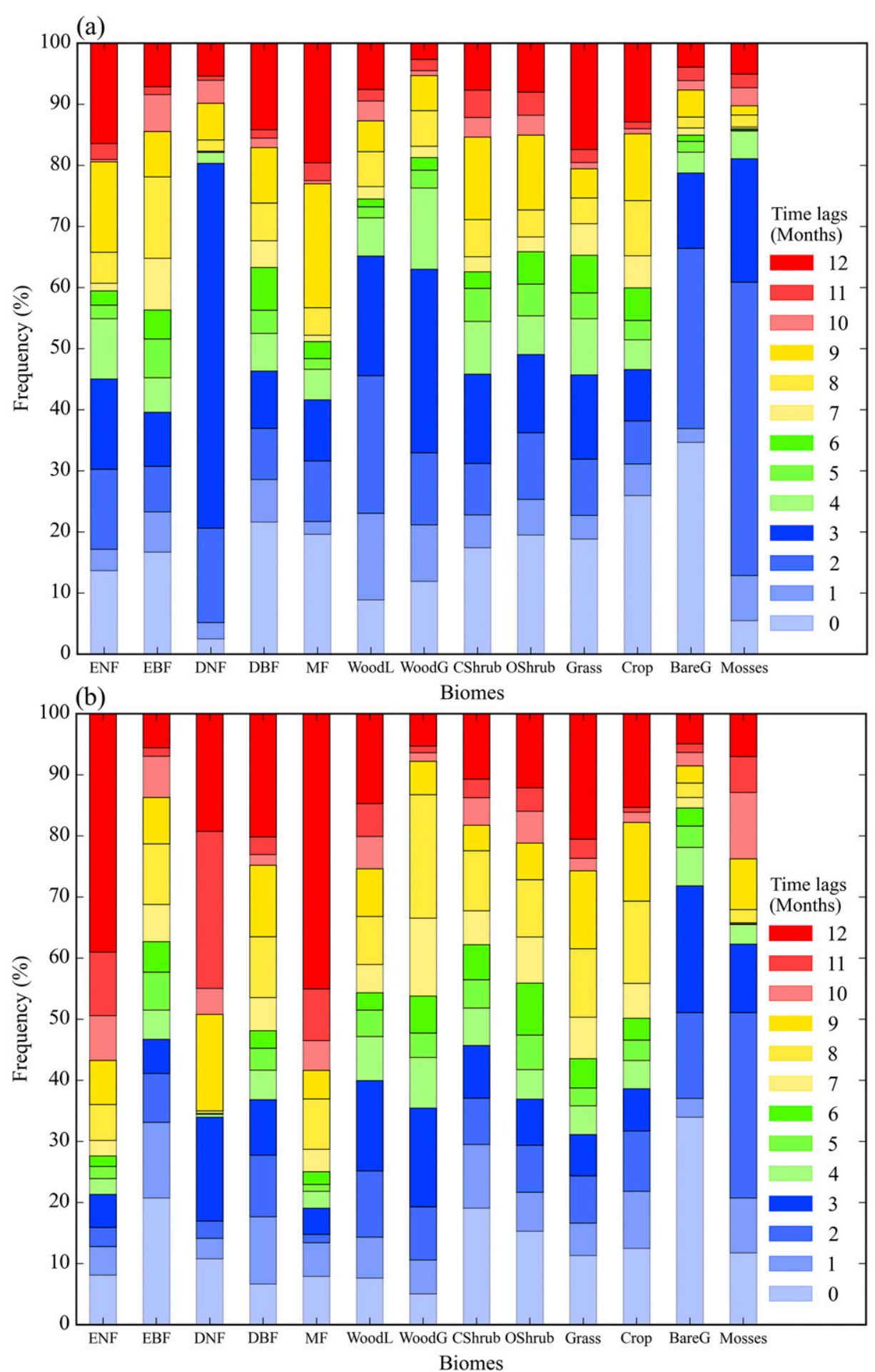

Figure 4. Frequency of different BTLs of terrestrial NPP in responding to (a) ATmax and (b) ATmin within different plant biomes. Only significant $(p$ value $<0.05$ ) pixels are taken into consideration. Vegetation biomes are introduced in Table 1. 


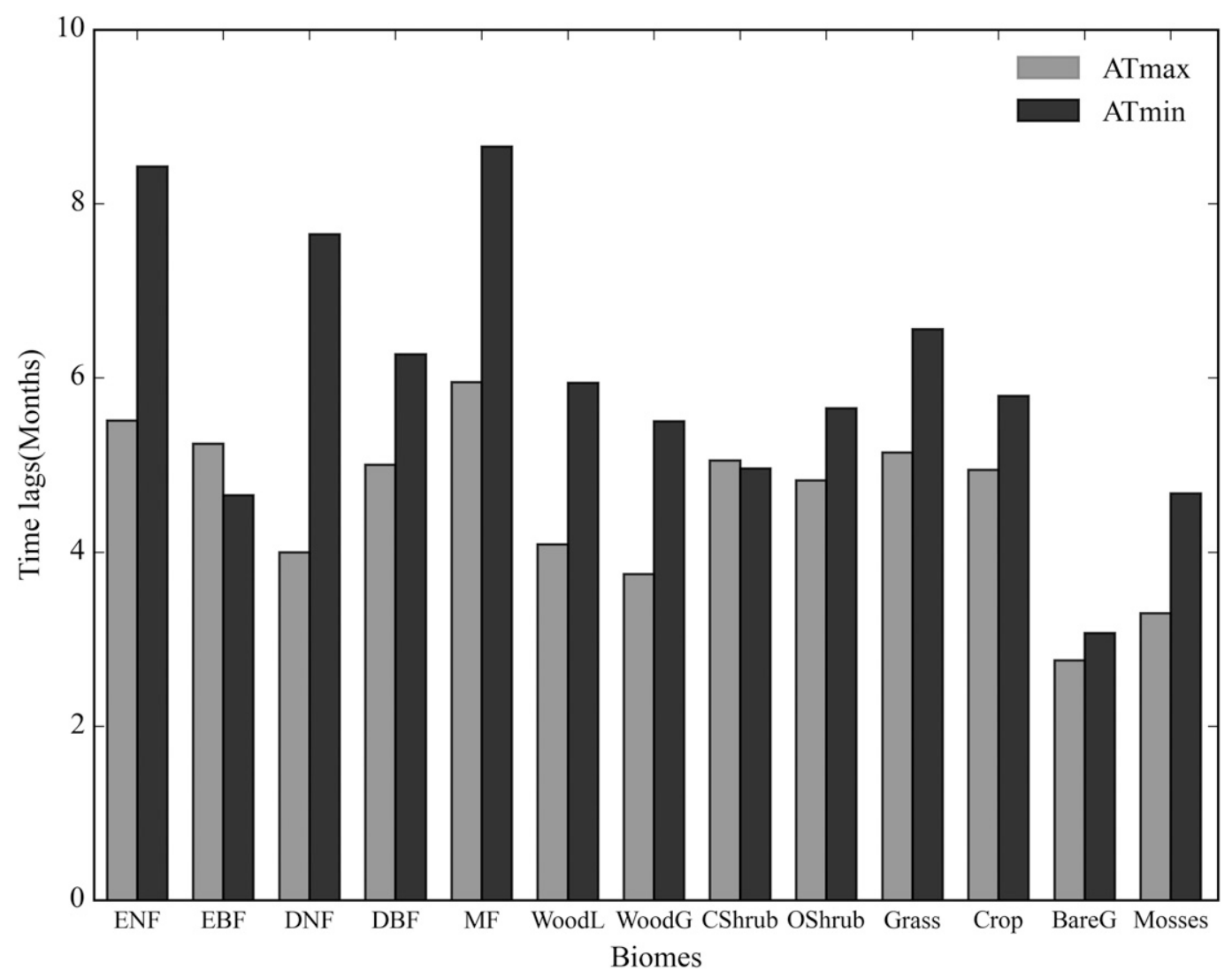

Figure 5. The average BTLs of terrestrial NPP when responding to ATmax (light gray bar) and ATmin (dark gray bar) within different plant biomes. Only significant ( $p$ value $<0.05$ ) pixels are considered. Vegetation biomes are introduced in Table 1.

in all biomes have delayed effects longer than 1 month in responding to ATmax and ATmin; quite a few biomes are inclined to have lags of up to 12 months. As shown in Figure 5, most of the biomes' lags are pronounced, with average time-lag durations of 4 to 7 months. Additionally, forest biomes as a whole respond to ATmax and ATmin with average time lags of $5.29 \pm 4.06$ months and $7.05 \pm 4.49$ months, respectively; nonforest biomes, however, exhibit shorter-term responses to these two temperature factors $(4.41 \pm 3.87$ months for ATmax and $5.78 \pm 4.16$ months for ATmin), which further confirms that the forest biomes, rather than nonforest biomes, have longer lagged responses to asymmetric warming.

In terms of the BTLs of vegetation productivities to ATmax (Figures 4a, 5), eyecatching percentages of more than $40 \%$ exist in the pixels of nearly all biomes that are covered by lagged durations of $0-3$ months, and the top five biomes are mosses and lichens (Mosses; 81.10\%), deciduous needleleaf forests (DNF; 80.32\%), bare ground (BareG;78.76\%), woodlands (WoodL; 65.16\%), and wooded grasslands (WoodG; 63.01\%). A large percentage of pixels in DNF (59.70\%) have 3-month lagged effects, with mean lagged time of $4.00 \pm 2.97$ months. Considerable 
Earth Interactions - Volume 22 (2018) • Paper No. 8 • Page 14

numbers of pixels for mixed forests (MF;19.58\%), evergreen needleleaf forests (ENF; 16.40\%), and deciduous broadleaf forests (DBF; 14.16\%) are covered by prolonged durations of 12 months, with average lagged months of $5.95 \pm 4.49$, $5.51 \pm 4.19$, and $5.00 \pm 4.22$ months, respectively. The pixels of evergreen broadleaf forests (EBF) that have protracted lag durations of $0-3$ months and 79-month durations account for $39.58 \%$ and $29.18 \%$ of the total grids in EBF, respectively, with an overall average prolonged duration of $5.24 \pm 3.81$ months. In addition, $47.98 \%$ of Mosses show 2-month time lags, and $34.67 \%$ of BareG exhibit no delay impacts; the mean time lags for them are $3.30 \pm 3.05$ and $2.76 \pm 3.35$ months, respectively. WoodL and WoodG seem relatively alike in the distributions of the frequency of different time lags; the same cases are found in closed shrublands (CShrub) and open shrublands (OShrub) and Grass and croplands (Crop), and each pair is inclined to have equal average lags $(4.09 \pm 3.63$ and $3.75 \pm 3.00$ months for WoodL and WoodG; $5.05 \pm 3.96$ and $4.82 \pm 3.99$ months for CShrub and OShrub; and $5.14 \pm 4.21$ and $4.94 \pm 4.25$ months for Grass and Crop).

According to Figure 4b and Figure 5, NPP responds to ATmin with significant time-lag effects as well. First, similar to ATmax, a considerably large proportion (larger than 30\%) of grids in all biomes (except for ENF and MF) have 0-3-month delays when responding to ATmin, with the highest percentages appearing in BareG (71.83\%), Mosses (62.30\%), and EBF (46.71\%); the total average lagged months for these three vegetation biomes were $3.07 \pm 3.41,4.67 \pm 4.16$, and 4.65 \pm 3.92 months, respectively. Second, MF and ENF have remarkable frequencies of grids that exhibit hysteretic effects of 12 months (45.04\% for MF and 39.01\% for ENF), which constitute strikingly high frequencies of pixels that are covered by lagged impacts of 10-12 months in MF (58.36\%) and ENF $(56.76 \%)$, followed by DNF $(49.23 \%)$. The average delays for these biomes are $8.66 \pm 4.21$ months for MF, $8.43 \pm 4.24$ months for ENF, and $7.65 \pm 4.41$ months for DNF. In addition, somewhat large percentages of the grids for DBF (20.16\%), Grass (20.55\%), and Crop (15.32\%) are found to be covered by time-lag durations of 12 months, with overall delays averaging at $6.27 \pm 4.18,6.56 \pm 4.16$, and $5.79 \pm 3.41$ months, respectively. Finally, it seems that the time-lag frequency patterns of WoodL to ATmin tend to be analogous to that of WoodG; this is also the case for CShrub to OShrub, and the mean time lags of these four biomes are 5.94 $\pm 4.05,5.50 \pm 3.16$, $4.96 \pm 4.10$, and $5.65 \pm 4.03$ months, respectively.

\subsection{Partial correlations between vegetation and asymmetric warming}

We obtained the spatial distributions of optimal PCC $\left(R_{\text {best }}\right)$ between NPP and ATmax, ATmin (Figures 6a,b). Figure 6a suggests that the positive correlations between NPP and ATmax are particularly strong in the biomes over northern boreal and polar regions and in some northern cold and boreal zones (i.e., the Great Plains), as well as in high-altitude areas (i.e., the Tibetan Plateau). The negative correlations between NPP and ATmax spread widely and strongly over arid regions in the northern cold-temperate and tropical ecosystems (i.e., the Amazon basin and the dry zones in Africa). Figure $6 \mathrm{~b}$ shows mostly the reverse of the pattern in Figure 6a; that is, the terrestrial NPP relates to ATmin negatively over 

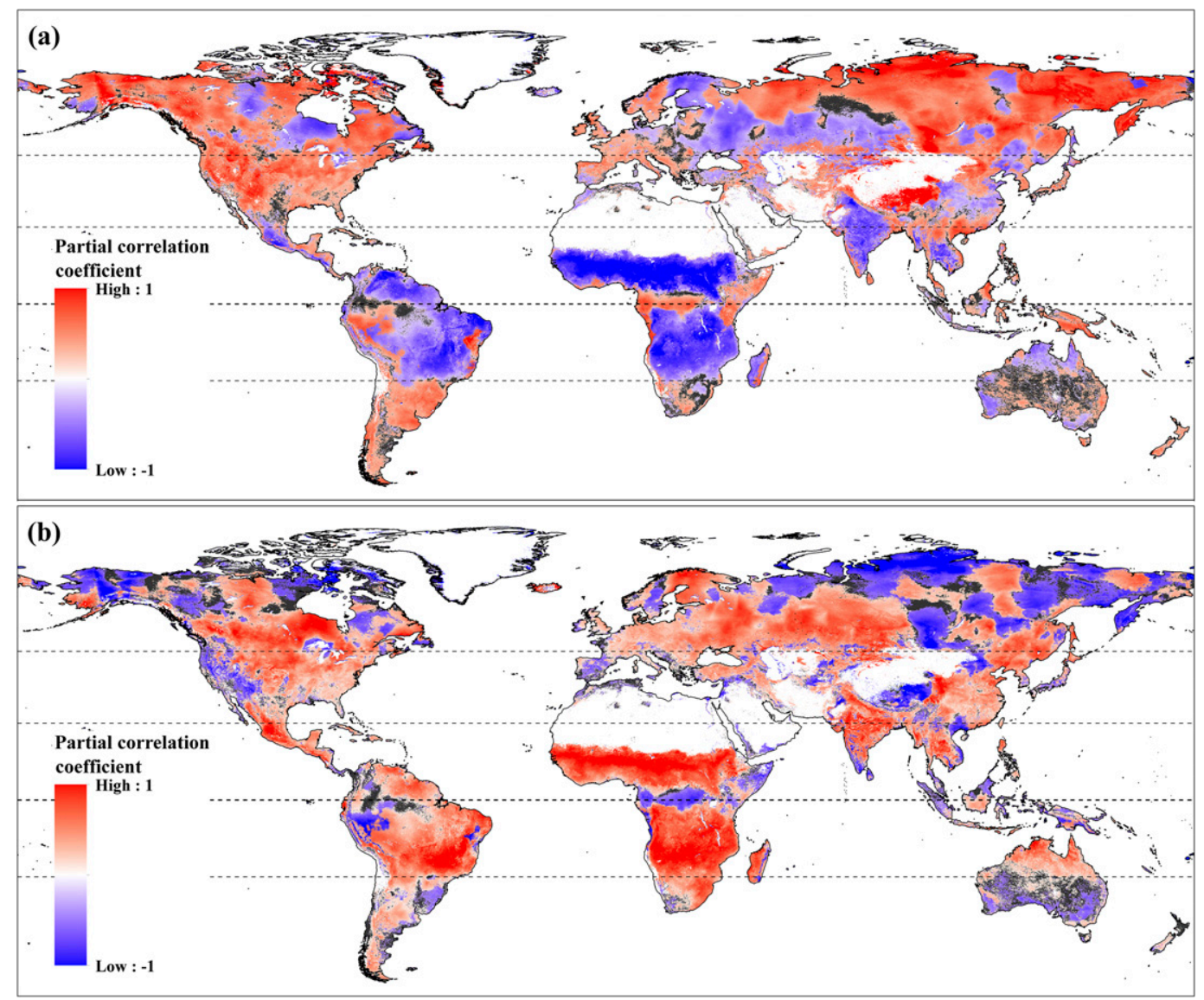

Figure 6. Spatial patterns of optimal PCC $\left(R_{\text {best }}\right)$ between terrestrial NPP and (a) ATmax and (b) ATmin for the period from 1982 to 2013. White areas refer to places with no data, and dark gray areas refer to places with no significant correlations.

the high-altitude areas (i.e., the Tibetan Plateau) and most places in northern mid- to high latitudes (i.e., the boreal and polar zones). On the contrary, NPP associates with ATmin positively over the vast, arid, warm-temperate and tropical regions.

Post hoc comparisons of the density analyses of the most favorable PCCs across different vegetation biomes (Figures 7a,b) illustrate that an overwhelming majority of pixels in DNF (89.74\%), followed by Mosses (86.80\%), ENF (74.33\%), and MF (72.26\%), respond positively to ATmax (Figure 7a), whereas most grids in BareG (75.47\%) and WoodG (72.90\%) are characterized by negative correlations with ATmax. In addition, a near-equal split of positive and negative correlations exists in the responses of all other biomes to ATmax. Additionally, Figure $7 \mathrm{~b}$ shows that ATmin has an overall positive impact on the productivity of most biomes, with the exceptions of Mosses and DNF, because the grids in Mosses (67.33\%) have a dominantly negative correlation with ATmin, and there is a nearly half-to-half distribution of positive and negative coefficients between DNF and ATmin. 

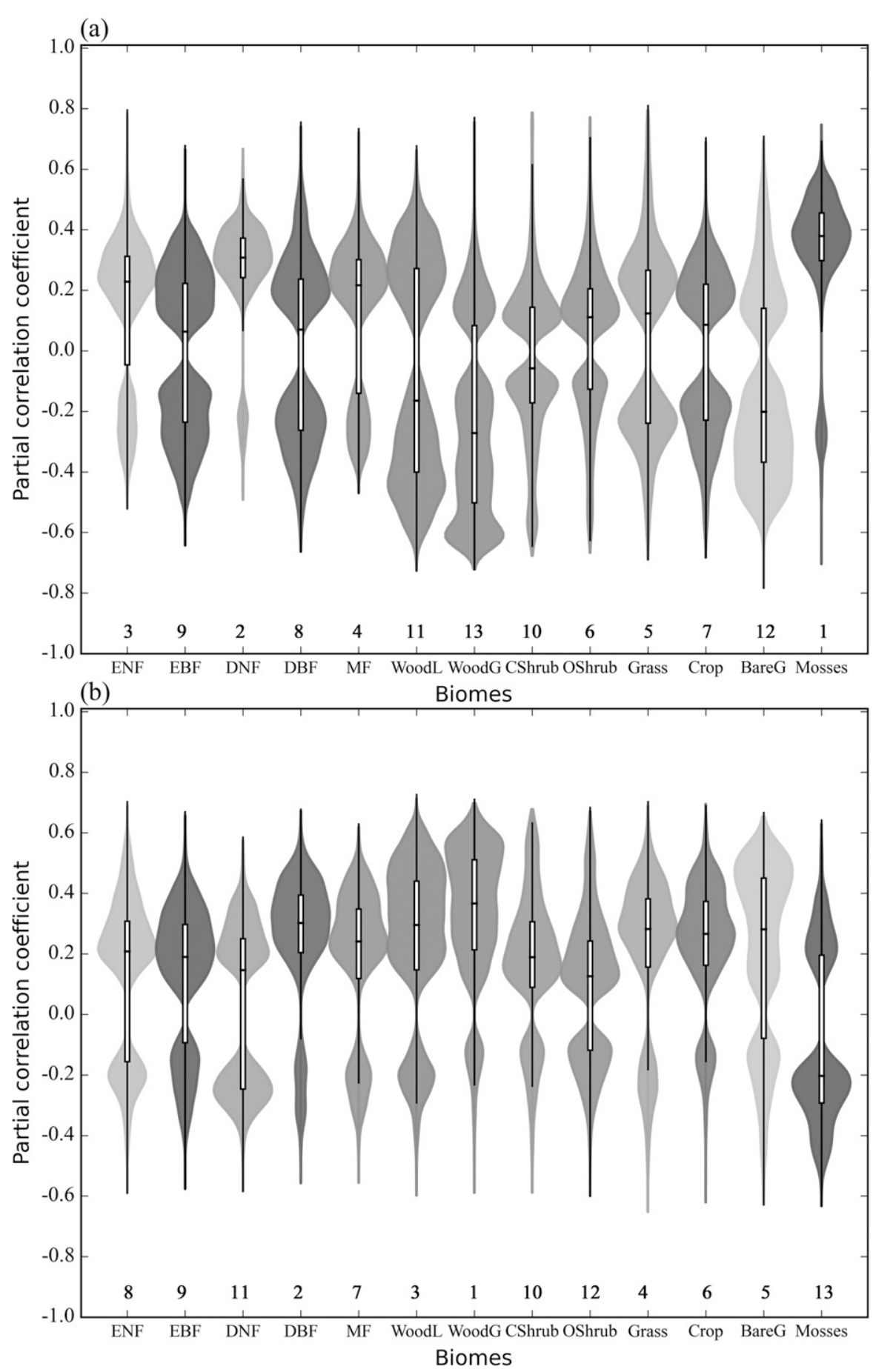

Figure 7. Violin plots of optimal PCC ( $\left.R_{\text {best }}\right)$ between terrestrial NPP and (a) ATmax and (b) ATmin within different plant biomes. The bold inner line of each box represents the average correlation. Average correlations from positive to negative are labeled in numerical order. Only significant ( $p$ value $<0.05$ ) pixels are shown. Vegetation biomes are introduced in Table 1. 
Earth Interactions - Volume 22 (2018) • Paper No. 8 - Page 17

\section{Discussion}

In contrast to previous studies (Peng et al. 2013; Su et al. 2015; Tan et al. 2015; Xia et al. 2014), we focused on the time-lag effects of asymmetric warming exhibits on the vegetation NPP, which were obtained by using the CASA model. Our results showed that asymmetric warming has universal time-lag effects on global plant growth, single vegetation biome exhibits distinguishing responses to asymmetric warming, and different biomes respond to asymmetric warming nonuniformly.

\subsection{Lagged duration of vegetation biomes to asymmetric warming}

ATmax and ATmin can indirectly influence the ecophysiological process and further regulate the carbon sequestration and consumption in plants, mainly by changing the enzyme activities for photosynthetic and autotrophic respiration (Foote and Schaedle 1976; Turnbull et al. 2002), shifting the phenology (Piao et al. 2015), and altering the availabilities of the soil nutrient (Chapin et al. 1995) and water content (Peng et al. 2013). These effects will take some time to be reflected in the vegetation growth (Wu et al. 2015; Xia et al. 2014). Additionally, the climate-anomaly tolerance (Bita and Gerats 2013) and acclimation (Slot and Kitajima 2015) abilities of green plants allow them to adapt to and cope with the fluctuations in ambient temperature for a certain time. Therefore, green plants exhibit certain plasticity to ambient temperature dynamics and certain tolerance to long-term exposure to passive feedback between climate warming and the carbon cycle (Wu et al. 2015; Xia et al. 2014). Furthermore, there exist complicated mechanisms that allocate the photosynthetic carbon uptake between above- and belowground parts of vegetation, likely through the temperatureinduced dynamics in enzyme activity and phloem viscosity within plants (Barthel et al. 2014) and variations in the soil nutrient availability and moisture content ( $\mathrm{Li}$ et al. 2011; Newman et al. 2006), while there are certain time intervals in the dynamic allocation of the carbon being transported between leaves and rhizospheres (Barthel et al. 2014; Kuzyakov and Gavrichkova 2010; Newman et al. 2006). Finally, the longterm tradeoff processes between plant growth and soil carbon $(C)$ and/or nitrogen $(\mathrm{N})$ availability (Vukićević et al. 2001; Zhang et al. 2016) and the long-term turnover time of deep soil moisture to surface were also recommended to affect the temperatureinduced time-lag effects (Braswell et al. 1997). These might be the most important mechanisms underlying the ubiquity of hysteretic impacts of asymmetric warming (ATmax and ATmin) on vegetation productivity (NPP).

In this study, we also suggest that there exist heterogeneous delay effects in the responses of terrestrial NPP to ATmax and ATmin across global plant biomes, which may owe to the different mechanisms of ATmax versus ATmin on vegetation growth and the uniqueness of different plant biomes (e.g., life form and structure, environmental adaption, and morphological, biochemical, physiological, and behavioral characteristics) (Pan et al. 2013; Woodward et al. 2004; Xu et al. 2015). We found that during the growing season, the polar and boreal biomes have a tendency to respond to asymmetric warming immediately, which might be the reason that the plant growth there was primarily limited by temperature and was very sensitive to the variations in ambient temperature (Nemani et al. 2003; Wu et al. 2015); this finding was consistent with the results of Braswell et al. (1997), who showed the boreal regions were inclined 
Earth Interactions - Volume 22 (2018) • Paper No. 8 • Page 18

to show zero-lag responses to temperature anomalies. Additionally, we showed that evergreen plants (ENF and EBF) have slightly longer time-lag effects than deciduous plants (DNF and DBF) do in responding to ATmax. This may be because evergreen plants, rather than deciduous plants, have higher levels of temperature warming acclimation abilities and more vigorous homeostasis to photosynthesis temperature fluctuation (Yamori et al. 2014), which allows evergreen plants to better adapt to ambient temperature fluctuations. The deciduous plants were very sensitive to temperature fluctuations, and they have developed the leaf-on and leaf-off strategies in responding to temperature (Piao et al. 2015; Polgar and Primack 2011), while the climate warming has extended the length of the vegetation growing season at both the start of leaf-on days and the end of leaf-off days (Polgar and Primack 2011; Wang et al. 2017). These phenological changes have brought about a greater degree of carbon sequestered, at the cost of larger soil nutrient decreases to deciduous forests than evergreen forests (Newman et al. 2006; Richardson et al. 2010; Richardson et al. 2009). This subtle difference tends to make the deciduous forests respond more tightly to the temperature fluctuations than evergreen forests do. Broadleaf forests generally require higher levels of maintenance respiration than needleleaf trees do (Reich et al. 1998), so the former requires a greater adaption to nighttime warming to cope with the loss in carbon, which probably results in the shorter prolonged duration in EBF and DBF to ATmin than in ENF and DNF. In addition, we noted that the forest biomes (i.e., ENF, DNF, EBF, DBF, and MF) exhibit slightly larger percentages of pixels with delays longer than 6 months and larger average lagged time when responding to asymmetric warming than nonforest biomes; this result is supported by the study of Peng et al. (2010), who also found that larger areas of evergreen and deciduous forests have longer lagged durations in responding to air temperature than do the vegetation biomes of grass, crop, and shrub. Distributed mostly in the boreal and polar regions, the growth of Mosses and DNF is mainly restricted by temperature, and their photosynthesis is sensitive to daytime warming; thus, they are found to have the greatest proportion of pixels covered by $0-3$ lagged months and show quite short average time-lag effects to ATmax. Growing in a relatively favorable living environment (Pan et al. 2013; Woodward et al. 2004), the MF may thrive with a longer period of moderate warming, so compared with other biomes, the MF has the longest mean time-lag duration in response to both asymmetric warming factors. Finally, our study was carried out based on the coarse-resolution data $(\sim 8 \mathrm{~km})$; therefore, some vegetation is still presented in the bare ground. We found that the BareG biome is negatively correlated with the temperature, which is likely due to the temperature-induced enhancement in the soil drought condition. The BareG biome may have formed a mechanism to quickly recover from the anomalies in temperature (Braswell et al. 1997; Wu et al. 2015); therefore, it is not surprising that the BareG biome has the largest proportion of pixels with zero delay impacts and shows the shortest average hysteretic duration in responding to both asymmetric warming temperature parameters.

\subsection{Partial correlations of vegetation biomes to asymmetric warming}

A biome is composed of similar life forms and commonly occurs in similar environmental and geographical conditions; it is unique in its morphological, physiological, and behavioral characteristics (Gang et al. 2013; Pan et al. 2013; 
Earth Interactions - Volume 22 (2018) - Paper No. 8 • Page 19

Woodward et al. 2004). These distinguishing features make biomes respond to climate warming with distinctive peculiarities (Gang et al. 2013; Lucht et al. 2006). DBF usually survives in temperate zones, characterized by seasonally distinctive temperature and soil moisture (Pan et al. 2013); such seasonality might explain the double extreme PCC between DBF and ATmax. The EBF is a hot and moist biome that exists mainly in tropical regions, and it has been well established that the biomass of tropical forests responds in opposition to recent climate warming (Potter et al. 2012; Xu et al. 2015; Zhao and Running 2010), which is again confirmed here (Figures 6a, 7a). We also found that the negative correlations between the EBF and ATmax are mainly distributed in the Amazonian rain forest and the arid zones in Africa, likely due to the increasing drought severity (Zhao and Running 2010). WoodL generally spreads over the latitudinal belt of $50^{\circ}-70^{\circ} \mathrm{N}$ and tropical savanna areas (Pan et al. 2013), and the plant growth in the former region is restricted by insufficient heat; on the contrary, the vegetation growth in the latter region is typically limited by the pronounced dry season throughout the year, so ATmax exhibits opposite effects on WoodL. WoodG is the grasslands with scattered woody plants and is generally distributed in fire-prone areas, such as the northern and southern fire belts of Africa and northern and eastern Australia (Verón et al. 2012), so ATmax negatively correlates with WoodG by reducing the soil moisture. Needleleaf forests are cold-resistant and drought-tolerant biomes (Pidwirny 2006), and they are prevalent in high-elevation alpine chains and boreal zones, where vegetation growth is mainly limited by temperature (Nemani et al. 2003; Wu et al. 2015); therefore, predominantly positive correlations between ENF and/or DNF and ATmax can be found. MF is a tree ecoregion that is dominated by two or more tree species and generally grows in Northern Hemisphere climate zones $\left(40^{\circ}-60^{\circ} \mathrm{N}\right)$ with a moderate temperature and appropriate annual rainfall (Loveland and Belward 1997); appropriate warming contributes to the growth of $\mathrm{MF}$, so the MF is positively associated with ATmax. The shrub, grass, and crop communities can be divided into $\mathrm{C} 3, \mathrm{C} 4$, and CAM plants, wherein the $\mathrm{C} 3$ plants adapt best to cool and wet environments. The other two, however, adapt best to hot, sunny, and dry environments (Bareja 2012), and these contrary growing habits may help explain the reverse correlations within OShrub, CShrub, Grass, and Crop to ATmax. This result is supported by Braswell et al. (1997), who also reported opposite correlations exhibited in the responses of $\mathrm{C} 3$ and $\mathrm{C} 4$ grasslands, savannas, and cultivation lands to temperature.

ATmin mainly influences vegetation growth via dominantly enhanced, dark autotrophic respiration (Turnbull et al. 2002), which was thought to have passive effects on the carbon subsidence in green plants (Anderegg et al. 2015; Peng et al. 2013). Interestingly, in this study, we found that there are dominant positive correlations between ATmin and NPP across biomes, except for DNF and Mosses (Chapin et al. 1995; Peng et al. 2013; Slot and Kitajima 2015; Tan et al. 2015). This may be because of the synthetically positive influences from nocturnal warming, that is, the strengthened photosynthesis in the following daytime periods [by depleting leaf carbohydrates (Turnbull et al. 2002; Wan et al. 2009), easing the frost risk, and enlarging the plant growing season (Gu et al. 2008; Kim et al. 2012)] and the nighttime respiration acclimation and adaption abilities of plants, which prevent the carbon loss in the plant and thus maintain growth. This finding is supported by some former research: for instance, Piao et al. (2007) reported that nighttime 
Earth Interactions - Volume 22 (2018) • Paper No. 8 • Page 20

Table 4. The abbreviations and the full names of the parameters that are used in this study, listed in alphabetical order.

\begin{tabular}{ll}
\hline Abbreviation & \\
\hline ATmax & Accumulated monthly daytime temperature \\
ATmin & Accumulated monthly nighttime temperature \\
BTL & Best time lag \\
CASA & Carnegie-Ames-Stanford Approach model \\
CRU & Climatic Research Unit \\
GIMMS & Global Inventory Monitoring and Modeling Studies group \\
GPPDI R2 & The revised Global Primary Production Data Initiative Products \\
MVC & Maximum value composites method \\
NCEP-NCAR & National Centers for Environmental Prediction-National Center for Atmospheric \\
& Research \\
NDVI & Normalized difference vegetation index \\
NDVI.3g.v1 & The first version of the third-generation GIMMS NDVI \\
NPP & Net primary production \\
PCC & Partial correlation coefficients \\
PRCP & Monthly total precipitation \\
$R^{2}$ & Determination coefficient \\
$R_{\text {best }}$ & Optimal partial correlation coefficients \\
SOLAR & Incoming shortwave solar radiation data \\
$T_{\text {base }}$ & Threshold temperature value for accumulated temperature \\
TEM & Monthly average temperatures \\
Tmax & Monthly maximum temperatures \\
Tmin & Monthly minimum temperatures \\
UMD_GVM & Vegetation biome map obtained from the University of Maryland Department of \\
& Geography \\
\hline
\end{tabular}

warming had significantly extended the vegetation growing season, which may eventually increase the growth in vegetation. Yang et al. (2016) found that an increasing nocturnal temperature can enhance the drought-resistance abilities of plant communities and stimulate terrestrial carbon sequestration, and Wan et al. (2009) detected that through depleting leaf carbohydrates in a nocturnal environment, passive grassland carbon sequestration can be actually overcompensated for by the following daytime photosynthesis.

Our study provides a new perspective on terrestrial vegetation productivity responses to asymmetric warming. Together with previous studies (Peng et al. 2013; Su et al. 2015; Tan et al. 2015; Xia et al. 2014), the present study highlights the importance of considering the time-lag effects and nonuniformity of vegetation responses to asymmetric warming when investigating the vegetation-climate interactions (for a list of parameters and abbreviations used in this study, refer to Table 4). However, it is also important to mention that there are some uncertainties in the present study. First, some bias may still remain in the input datasets; for example, the GIMMS NDVI was reported to have limited abilities in reflecting true vegetation changes over the tropical and Arctic ecosystems (Fensholt and Proud 2012), whereas the CRU was criticized for its overestimates and underestimates over the regions with poor station coverage (i.e., Africa; Zhang et al. 2013) and high spatial variability (i.e., in arid, cold, and mountainous places; Tanarhte et al. 2012). Second, we unified the UMD_GVM dataset throughout the whole study to minimize the effects from land-cover changes, but there still exist land-cover changes that occurred in recent years that could not be eliminated, which could 
Earth Interactions - Volume 22 (2018) • Paper No. 8 • Page 21

increase the uncertainties of our results. Third, the CASA model used in this study may not adequately predict the changes in vegetation production because it neglects the feedbacks of $\mathrm{CO}_{2}$ fertilization (Thomas et al. 2016), nitrogen (N) deposition (Finzi et al. 2007), and mineralization (Chapin et al. 1995) to NPP (Potter et al. 1999; Zhao et al. 2005), which limits CASA to investigate the potential lag mechanisms against $\mathrm{CO}_{2}$ and $\mathrm{N}$ fluctuations. The last estimated NPP may not fully reflect the true conditions of vegetation production, as revealed by the discrepancies between estimated NPP and the field NPP (Figure 2), especially in the biomes of Crop and Mosses, which are likely due to the unpredictable artificial managements (i.e., the irrigation and fertilization) to cropland (Rost et al. 2009) and the inabilities of GIMMS NDVI to reflect the true vegetation vigor of Mosses (Fensholt and Proud 2012). These situations tend to bias our results to some degree. Furthermore, the vegetation-climate relationship, strictly speaking, is not a linear relationship, so the linear statistical analyses in this paper are not wholly sufficient to depict the interrelationship between NPP and daytime versus nighttime warming. Finally, the quantitative impacts of human activities (Li et al. 2017; Liu et al. 2017) and natural hazards (Tchebakova et al. 2009; Verón et al. 2012) on vegetation productivity were not considered in the present study. In short, our knowledge of the mechanisms behind the lagged responses of vegetation to asymmetric warming is still poor; therefore, further study is required for a full understanding of the mechanisms behind the time-lag effects of asymmetric warming on terrestrial biomes' productivity, and improving the input data's accuracy, integrating various studies, and combining multimodel results will be extremely helpful.

\section{Conclusions}

In this study, we obtained the global time-lag effects (within 1 year) of terrestrial productivity responding to asymmetric warming by using the CASA-modeled NPP and ATmax and ATmin from 1982 to 2013, and statistical analyses (i.e., partial correlation and time-lag analyses) were applied here to perform the investigation. Conclusions are as follows:

1) Asymmetric warming has nonuniform time-lag effects on single biomes, and different biomes respond to asymmetric warming heterogeneously.

2) Generally, the biomes respond to ATmax (4.63 \pm 3.92 months) with a shorter lagged duration than to ATmin (6.06 \pm 4.27 months).

3 ) On the whole, the forest biomes exhibit longer lagged durations in responding to asymmetric warming than the other biomes do, and the average BTLs are longest in MF and ENF and shortest in BareG and Mosses.

4) Most Mosses, ENF, DNF, and MF positively correlate with ATmax, while WoodG is dominated by negative correlations with ATmax, and the other biomes respond to ATmax with a near-equal split of positive and negative correlations. Furthermore, ATmin has a predominantly positive influence on terrestrial biomes, except for the biomes of Mosses and DNF.

5) The quite contrary mechanisms of daytime versus nighttime warming on vegetation growth and the uniqueness of each biome (e.g., life form and structure, environmental adaption, and morphological, biochemical, physiological, and behavioral characteristics) might account for these results. 


\section{Earth Interactions • Volume 22 (2018) • Paper No. 8 • Page 22}

Acknowledgments. This work was funded by the National Key R \& D Program of China (2017YFA0604404), the Key National Natural Science Foundation of China (Grant 41531176), and the National Natural Science Foundation of China (Grant 41671398).

\section{References}

Anderegg, W. R. L., and Coauthors, 2015: Tropical nighttime warming as a dominant driver of variability in the terrestrial carbon sink. Proc. Natl. Acad. Sci. USA, 112, 15 591-15 596, https://doi.org/10.1073/pnas.1521479112.

Atzberger, C., A. Klisch, M. Mattiuzzi, and F. Vuolo, 2013: Phenological metrics derived over the European continent from NDVI3g data and MODIS time series. Remote Sens., 6, 257-284, https://doi.org/10.3390/rs6010257.

Bareja, B. G., 2012: The history of photosynthesis: Contributions of early researchers. CropsReview, accessed 15 May 2017, http://www.cropsreview.com/history-of-photosynthesis.html.

Barthel, M., E. Cieraad, A. Zakharova, and J. E. Hunt, 2014: Sudden cold temperature delays plant carbon transport and shifts allocation from growth to respiratory demand. Biogeosciences, 11, 1425-1433, https://doi.org/10.5194/bg-11-1425-2014.

Bita, C. E., and T. Gerats, 2013: Plant tolerance to high temperature in a changing environment: Scientific fundamentals and production of heat stress-tolerant crops. Front. Plant Sci., 4, 273, https://doi.org/10.3389/fpls.2013.00273.

Braswell, B. H., D. S. Schimel, E. Linder, and B. Moore, 1997: The response of global terrestrial ecosystems to interannual temperature variability. Science, 278, 870-873, https://doi.org/ 10.1126/science.278.5339.870.

Caesar, J., L. Alexander, and R. Vose, 2006: Large-scale changes in observed daily maximum and minimum temperatures: Creation and analysis of a new gridded data set. J. Geophys. Res., 111, D05101, https://doi.org/10.1029/2005JD006280.

Chapin, F. S., G. R. Shaver, A. E. Giblin, K. J. Nadelhoffer, and J. A. Laundre, 1995: Responses of Arctic tundra to experimental and observed changes in climate. Ecology, 76, 694-711, https:// doi.org/10.2307/1939337.

Cramer, W., and Coauthors, 1999: Comparing global models of terrestrial net primary productivity (NPP): Overview and key results. Global Change Biol., 5, 1-15, https://doi.org/10.1046/ j.1365-2486.1999.00009.x.

De Fries, R. S., M. Hansen, J. R. G. Townshend, and R. Sohlberg, 1998: Global land cover classifications at $8 \mathrm{~km}$ spatial resolution: The use of training data derived from Landsat imagery in decision tree classifiers. Int. J. Remote Sens., 19, 3141-3168, https://doi.org/10.1080/014311698214235.

Easterling, D. R., and Coauthors, 1997: Maximum and minimum temperature trends for the globe. Science, 277, 364-367, https://doi.org/10.1126/science.277.5324.364.

FAO, IIASA, ISRIC, ISSCAS, and JRC, 2012: Harmonized World Soil Database (version 1.2). FAO and IIASA, http://webarchive.iiasa.ac.at/Research/LUC/External-World-soil-database/HTML/.

Fensholt, R., and S. R. Proud, 2012: Evaluation of Earth Observation based global long term vegetation trends-Comparing GIMMS and MODIS global NDVI time series. Remote Sens. Environ., 119, 131-147, https://doi.org/10.1016/j.rse.2011.12.015.

Finzi, A. C., and Coauthors, 2007: Increases in nitrogen uptake rather than nitrogen-use efficiency support higher rates of temperate forest productivity under elevated $\mathrm{CO}_{2}$. Proc. Natl. Acad. Sci. USA, 104, 14 014-14 019, https://doi.org/10.1073/pnas.0706518104.

Foote, K. C., and M. Schaedle, 1976: Physiological characteristics of photosynthesis and respiration in stems of Populus tremuloides Michx. Plant Physiol., 58, 91-94, https://doi.org/10.1104/pp.58.1.91.

Friedl, M. A., and Coauthors, 2002: Global land cover mapping from MODIS: Algorithms and early results. Remote Sens. Environ., 83, 287-302, https://doi.org/10.1016/S0034-4257(02)00078-0.

Gang, C., W. Zhou, J. Li, Y. Chen, S. Mu, J. Ren, J. Chen, and P. Y. Groisman, 2013: Assessing the spatiotemporal variation in distribution, extent and NPP of terrestrial ecosystems in 


\section{Earth Interactions • Volume 22 (2018) • Paper No. 8 • Page 23}

response to climate change from 1911 to 2000. PLOS ONE, 8, e80394, https://doi.org/ 10.1371/journal.pone.0080394.

— - and Coauthors, 2015: Projecting the dynamics of terrestrial net primary productivity in response to future climate change under the RCP2.6 scenario. Environ. Earth Sci., 74, 59495959, https://doi.org/10.1007/s12665-015-4618-x.

Garcia-Mozo, H., C. Galan, M. T. Gomez-Casero, and E. Dominguez, 2000: A comparative study of different temperature accumulation methods for predicting the start of the Quercus pollen season in Cordoba (south west Spain). Grana, 39, 194-199, https://doi.org/10.1080/ 00173130051084322.

Gu, L., P. J. Hanson, W. M. Post, D. P. Kaiser, B. Yang, R. Nemani, S. G. Pallardy, and T. Meyers, 2008: The 2007 eastern US spring freeze: Increased cold damage in a warming world? BioScience, 58, 253-262, https://doi.org/10.1641/B580311.

Harris, I., P. D. Jones, T. J. Osborn, and D. H. Lister, 2014: Updated high-resolution grids of monthly climatic observations-The CRU TS3.10 Dataset. Int. J. Climatol., 34, 623-642, https://doi.org/10.1002/joc.3711.

Holben, B. N., 1986: Characteristics of maximum-value composite images from temporal AVHRR data. Int. J. Remote Sens., 7, 1417-1434, https://doi.org/10.1080/01431168608948945.

IPCC, 2014: Climate Change 2014: Synthesis Report. R. K. Pachauri and L. A. Meyer, Eds., IPCC, $151 \mathrm{pp}$.

Kim, Y., J. S. Kimball, K. Zhang, and K. C. McDonald, 2012: Satellite detection of increasing Northern Hemisphere non-frozen seasons from 1979 to 2008: Implications for regional vegetation growth. Remote Sens. Environ., 121, 472-487, https://doi.org/10.1016/j.rse.2012.02.014.

Kuzyakov, Y., and O. Gavrichkova, 2010: Time lag between photosynthesis and carbon dioxide efflux from soil: A review of mechanisms and controls. Global Change Biol., 16, 3386-3406, https://doi.org/10.1111/j.1365-2486.2010.02179.x.

Li, J., S. Lin, F. Taube, Q. Pan, and K. Dittert, 2011: Above and belowground net primary productivity of grassland influenced by supplemental water and nitrogen in Inner Mongolia. Plant Soil, 340, 253-264, https://doi.org/10.1007/s11104-010-0612-y.

Li, S., S. Lü, Y. Liu, Y. Gao, and Y. Ao, 2015: Variations and trends of terrestrial NPP and its relation to climate change in the 10 CMIP5 models. J. Earth Syst. Sci., 124, 395-403, https:// doi.org/10.1007/s12040-015-0545-1.

Li, X., G. Chen, X. Liu, X. Liang, S. Wang, Y. Chen, F. Pei, and X. Xu, 2017: A new global land-use and land-cover change product at a 1-km resolution for 2010 to 2100 based on humanenvironment interactions. Ann. Amer. Assoc. Geogr., 107, 1040-1059, https://doi.org/ 10.1080/24694452.2017.1303357.

Liao, C., and Q. Zhuang, 2015: Reduction of global plant production due to droughts from 2001 to 2010: An analysis with a process-based global terrestrial ecosystem model. Earth Interact., 19, 1-21, https://doi.org/10.1175/EI-D-14-0030.1.

Liu, X., and Coauthors, 2017: A future land use simulation model (FLUS) for simulating multiple land use scenarios by coupling human and natural effects. Landscape Urban Plann., 168, 94116, https://doi.org/10.1016/j.landurbplan.2017.09.019.

Loveland, T. R., and A. S. Belward, 1997: The IGBP-DIS global $1 \mathrm{~km}$ land cover data set, DISCover: First results. Int. J. Remote Sens., 18, 3289-3295, https://doi.org/10.1080/014311697217099.

Lucht, W., S. Schaphoff, T. Erbrecht, U. Heyder, and W. Cramer, 2006: Terrestrial vegetation redistribution and carbon balance under climate change. Carbon Balance Manage., 1, 6, https://doi.org/10.1186/1750-0680-1-6.

Matiu, M., D. P. Ankerst, and A. Menzel, 2016: Asymmetric trends in seasonal temperature variability in instrumental records from ten stations in Switzerland, Germany and the UK from 1864 to 2012. Int. J. Climatol., 36, 13-27, https://doi.org/10.1002/joc.4326.

Musau, J., S. Patil, J. Sheffield, and M. Marshall, 2016: Spatio-temporal vegetation dynamics and relationship with climate over East Africa. Hydrol. Earth Syst. Sci. Discuss., https://doi.org/ 10.5194/hess-2016-502. 


\section{Earth Interactions - Volume 22 (2018) • Paper No. 8 • Page 24}

Nemani, R. R., C. D. Keeling, H. Hashimoto, W. M. Jolly, S. C. Piper, C. J. Tucker, R. B. Myneni, and S. W. Running, 2003: Climate-driven increases in global terrestrial net primary production from 1982 to 1999. Science, 300, 1560-1563, https://doi.org/10.1126/science.1082750.

Newman, G. S., M. A. Arthur, and R. N. Muller, 2006: Above- and belowground net primary production in a temperate mixed deciduous forest. Ecosystems, 9, 317-329, https://doi.org/ 10.1007/s10021-006-0015-3.

Olson, R. J., J. M. O. Scurlock, S. D. Prince, D. L. Zheng, and K. R. Johnson, Eds., 2013: NPP multi-biome: Global primary production data initiative products, R2. Oak Ridge National Laboratory, Distributed Active Archive Center, https://doi.org/10.3334/ ORNLDAAC/617.

Pan, Y., R. A. Birdsey, O. L. Phillips, and R. B. Jackson, 2013: The structure, distribution, and biomass of the world's forests. Аnпи. Rev. Ecol. Evol. Syst., 44, 593-622, https://doi.org/ 10.1146/annurev-ecolsys-110512-135914.

Peng, D., and Coauthors, 2010: Spatial and seasonal characterization of net primary productivity and climate variables in southeastern China using MODIS data. J. Zhejiang Univ. Sci. B, 11, 275-285, https://doi.org/10.1631/jzus.B0910501.

Peng, S., and Coauthors, 2013: Asymmetric effects of daytime and night-time warming on Northern Hemisphere vegetation. Nature, 501, 88-92, https://doi.org/10.1038/nature12434.

Phillips, C. L., V. Murphey, K. Lajtha, and J. W. Gregg, 2016: Asymmetric and symmetric warming increases turnover of litter and unprotected soil C in grassland mesocosms. Biogeochemistry, 128, 217-231, https://doi.org/10.1007/s10533-016-0204-x.

Piao, S., P. Friedlingstein, P. Ciais, N. Viovy, and J. Demarty, 2007: Growing season extension and its impact on terrestrial carbon cycle in the Northern Hemisphere over the past 2 decades. Global Biogeochem. Cycles, 21, GB3018, https://doi.org/10.1029/2006GB002888.

— perature. Nat. Commun., 6, 6911, https://doi.org/10.1038/ncomms7911.

Pidwirny, M., 2006: Characteristics of the Earth's terrestrial biomes. Fundamentals of Physical Geography, 2nd ed. J. Petersen, D. Sack, and R. E. Gabler, Eds., Cengage, 544 pp.

Polgar, C. A., and R. B. Primack, 2011: Leaf-out phenology of temperate woody plants: From trees to ecosystems. New Phytol., 191, 926-941, https://doi.org/10.1111/j.1469-8137.2011.03803.x.

Potter, C. S., J. T. Randerson, C. B. Field, P. A. Matson, P. M. Vitousek, H. A. Mooney, and S. A. Klooster, 1993: Terrestrial ecosystem production: A process model based on global satellite and surface data. Global Biogeochem. Cycles, 7, 811-841, https://doi.org/ 10.1029/93GB02725.

—, S. Klooster, and V. Brooks, 1999: Interannual variability in terrestrial net primary production: Exploration of trends and controls on regional to global scales. Ecosystems, 2, 36-48, https:// doi.org/10.1007/s100219900056.

— _ _ _ and V. Genovese, 2012: Net primary production of terrestrial ecosystems from 2000 to 2009. Climatic Change, 115, 365-378, https://doi.org/10.1007/s10584-012-0460-2.

Reich, P. B., M. B. Walters, D. S. Ellsworth, J. M. Vose, J. C. Volin, C. Gresham, and W. D. Bowman, 1998: Relationships of leaf dark respiration to leaf nitrogen, specific leaf area and leaf lifespan: A test across biomes and functional groups. Oecologia, 114, 471-482, https://doi.org/ 10.1007/s004420050471.

Richardson, A. D., D. Y. Hollinger, D. B. Dail, J. T. Lee, J. W. Munger, and J. O'Keefe, 2009: Influence of spring phenology on seasonal and annual carbon balance in two contrasting New England forests. Tree Physiol., 29, 321-331, https://doi.org/10.1093/treephys/tpn040.

— ecosystem productivity. Philos. Trans. Roy. Soc. London, 365, 3227-3246, https://doi.org/ 10.1098/rstb.2010.0102.

Rost, S., D. Gerten, H. Hoff, W. Lucht, M. Falkenmark, and J. Rockström, 2009: Global potential to increase crop production through water management in rainfed agriculture. Environ. Res. Lett., 4, 044002, https://doi.org/10.1088/1748-9326/4/4/044002. 


\section{Earth Interactions - Volume 22 (2018) • Paper No. 8 • Page 25}

Sheffield, J., G. Goteti, and E. F. Wood, 2006: Development of a 50-year high-resolution global dataset of meteorological forcings for land surface modeling. J. Climate, 19, 3088-3111, https://doi.org/10.1175/JCLI3790.1.

Sherry, R. A., E. Weng, J. A. Arnone III, D. W. Johnson, D. S. Schimel, P. S. Verburg, L. L. Wallace, and Y. Luo, 2008: Lagged effects of experimental warming and doubled precipitation on annual and seasonal aboveground biomass production in a tallgrass prairie. Global Change Biol., 14, 2923-2936, https://doi.org/10.1111/j.1365-2486.2008.01703.x.

Slot, M., and K. Kitajima, 2015: General patterns of acclimation of leaf respiration to elevated temperatures across biomes and plant types. Oecologia, 177, 885-900, https://doi.org/ 10.1007/s00442-014-3159-4.

Song, Y., M. Ma, and F. Veroustraete, 2010: Comparison and conversion of AVHRR GIMMS and SPOT VEGETATION NDVI data in China. Int. J. Remote Sens., 31, 2377-2392, https:// doi.org/10.1080/01431160903002409.

Su, H., J. Feng, J. C. Axmacher, and W. Sang, 2015: Asymmetric warming significantly affects net primary production, but not ecosystem carbon balances of forest and grassland ecosystems in northern China. Sci. Rep., 5, 9115, https://doi.org/10.1038/srep09115.

Tan, J., and Coauthors, 2015: Seasonally different response of photosynthetic activity to daytime and night-time warming in the Northern Hemisphere. Global Change Biol., 21, 377-387, https://doi.org/10.1111/gcb.12724.

Tanarhte, M., P. Hadjinicolaou, and J. Lelieveld, 2012: Intercomparison of temperature and precipitation data sets based on observations in the Mediterranean and the Middle East. $J$. Geophys. Res., 117, D12102, https://doi.org/10.1029/2011JD017293.

Tchebakova, N. M., E. Parfenova, and A. J. Soja, 2009: The effects of climate, permafrost and fire on vegetation change in Siberia in a changing climate. Environ. Res. Lett., 4, 045013, https:// doi.org/10.1088/1748-9326/4/4/045013.

Thomas, R. T., and Coauthors, 2016: Increased light-use efficiency in northern terrestrial ecosystems indicated by CO2 and greening observations. Geophys. Res. Lett., 43, 11 339-11 349, https://doi.org/10.1002/2016GL070710.

Troy, T. J., and E. F. Wood, 2009: Comparison and evaluation of gridded radiation products across northern Eurasia. Environ. Res. Lett., 4, 045008, https://doi.org/10.1088/1748-9326/4/4/045008.

Tucker, C. J., J. E. Pinzon, M. E. Brown, D. A. Slayback, E. W. Pak, R. Mahoney, E. F. Vermote, and N. E. Saleous, 2005: An extended AVHRR 8-km NDVI dataset compatible with MODIS and SPOT vegetation NDVI data. Int. J. Remote Sens., 26, 4485-4498, https://doi.org/10.1080/ 01431160500168686.

Turnbull, M. H., R. Murthy, and K. L. Griffin, 2002: The relative impacts of daytime and night-time warming on photosynthetic capacity in Populus deltoides. Plant Cell Environ., 25, 17291737, https://doi.org/10.1046/j.1365-3040.2002.00947.x.

van Wijngaarden, W. A., and A. Mouraviev, 2016: Seasonal and annual trends in Australian minimum/maximum daily temperatures. Open Atmos. Sci. J., 10, 39-55, doi:10.2174/ 1874282301610010039.

Verón, S. R., E. G. Jobbágy, C. M. Di Bella, J. M. Paruelo, and R. B. Jackson, 2012: Assessing the potential of wildfires as a sustainable bioenergy opportunity. Global Change Biol. Bioenergy, 4, 634-641, https://doi.org/10.1111/j.1757-1707.2012.01181.x.

Vukićević, T., B. H. Braswell, and D. Schimel, 2001: A diagnostic study of temperature controls on global terrestrial carbon exchange. Tellus, 53B, 150-170, https://doi.org/10.3402/ tellusb.v53i2.16570.

Wan, S., J. Xia, W. Liu, and S. Niu, 2009: Photosynthetic overcompensation under nocturnal warming enhances grassland carbon sequestration. Ecology, 90, 2700-2710, https://doi.org/ 10.1890/08-2026.1.

Wang, J., and Coauthors, 2014: Comparison of gross primary productivity derived from GIMMS NDVI3g, GIMMS, and MODIS in Southeast Asia. Remote Sens., 6, 2108-2133, https:// doi.org/10.3390/rs6032108. 


\section{Earth Interactions - Volume 22 (2018) • Paper No. 8 • Page 26}

Wang, X., Q. Gao, C. Wang, and M. Yu, 2017: Spatiotemporal patterns of vegetation phenology change and relationships with climate in the two transects of East China. Global Ecol. Conserv., 10, 206-219, https://doi.org/10.1016/j.gecco.2017.01.010.

Wang, Z., T. Luo, R. Li, Y. Tang, and M. Du, 2013: Causes for the unimodal pattern of biomass and productivity in alpine grasslands along a large altitudinal gradient in semi-arid regions. J. Veg. Sci., 24, 189-201, https://doi.org/10.1111/j.1654-1103.2012.01442.x.

Woodward, F. I., M. R. Lomas, and C. K. Kelly, 2004: Global climate and the distribution of plant biomes. Philos. Trans. Roy. Soc. London., 359B, 1465-1476, https://doi.org/10.1098/ rstb.2004.1525.

Wu, D., X. Zhao, S. Liang, T. Zhou, K. Huang, B. Tang, and W. Zhao, 2015: Time-lag effects of global vegetation responses to climate change. Global Change Biol., 21, 3520-3531, https:// doi.org/10.1111/gcb.12945.

Xia, J., J. Chen, S. Piao, P. Ciais, Y. Luo, and S. Wan, 2014: Terrestrial carbon cycle affected by non-uniform climate warming. Nat. Geosci., 7, 173-180, https://doi.org/10.1038/ngeo2093.

Xie, X., Y. Zhang, R. Li, X. Yang, S. Shen, Y. Bao, X. Shen, and X. Jiang, 2014: Asymmetric warming effects on $\mathrm{N}$ dynamics and productivity in rice (Oryza sativa $\mathrm{L}$.). Soil Sci. Plant Nutr., 60, 530-539, https://doi.org/10.1080/00380768.2014.907531.

Xu, L., S. S. Saatchi, Y. Yang, R. B. Myneni, C. Frankenberg, D. Chowdhury, and J. Bi, 2015: Satellite observation of tropical forest seasonality: Spatial patterns of carbon exchange in Amazonia. Environ. Res. Lett., 10, 084005, https://doi.org/10.1088/1748-9326/10/8/084005.

Yamori, W., K. Hikosaka, and D. A. Way, 2014: Temperature response of photosynthesis in $\mathrm{C}_{3}, \mathrm{C}_{4}$, and CAM plants: Temperature acclimation and temperature adaptation. Photosynth. Res., 119, 101-117, https://doi.org/10.1007/s11120-013-9874-6.

Yang, Z., Q. Zhang, F. Su, C. Zhang, Z. Pu, J. Xia, S. Wan, and L. Jiang, 2016: Daytime warming lowers community temporal stability by reducing the abundance of dominant, stable species. Global Change Biol., 23, 154-163, https://doi.org/10.1111/gcb.13391.

Zeng, F., G. J. Collatz, J. E. Pinzon, and A. Ivanoff, 2013: Evaluating and quantifying the climatedriven interannual variability in Global Inventory Modeling and Mapping Studies (GIMMS) normalized difference vegetation index (NDVI3g) at global scales. Remote Sens., 5, 39183950, https://doi.org/10.3390/rs5083918.

Zhang, Q., H. Körnich, and K. Holmgren, 2013: How well do reanalyses represent the southern African precipitation? Climate Dyn., 40, 951-962, https://doi.org/10.1007/s00382-012-1423-z.

Zhang, T., and Coauthors, 2015: Lagged climatic effects on carbon fluxes over three grassland ecosystems in China. J. Plant Ecol., 8, 291-302, https://doi.org/10.1093/jpe/rtu026.

—, S. Yang, R. Guo, and J. Guo, 2016: Correction: Warming and nitrogen addition alter photosynthetic pigments, sugars and nutrients in a temperate meadow ecosystem. PLOS ONE, 11, e0158249, https://doi.org/10.1371/journal.pone.0158249.

Zhao, M., and S. W. Running, 2010: Drought-induced reduction in global terrestrial net primary production from 2000 through 2009. Science, 329, 940-943, https://doi.org/10.1126/science.1192666.

— , F. A. Heinsch, R. R. Nemani, and S. W. Running, 2005: Improvements of the MODIS terrestrial gross and net primary production global data set. Remote Sens. Environ., 95, 164176, https://doi.org/10.1016/j.rse.2004.12.011.

Zhao, W., X. Zhao, B. Tang, D. Wu, and H. Wei, 2015: Solar radiation contributed to the 2005 and 2010 Amazon droughts. Geoscience and Remote Sensing Symp. (IGARSS), Milan, Italy, IEEE, 1964-1967.

Zhou, L., R. K. Kaufmann, Y. Tian, R. B. Myneni, and C. J. Tucker, 2003: Relation between interannual variations in satellite measures of northern forest greenness and climate between 1982 and 1999. J. Geophys. Res., 108, 4004, https://doi.org/10.1029/2002JD002510.

Earth Interactions is published jointly by the American Meteorological Society, the American Geophysical Union, and the Association of American Geographers. For information regarding reuse of this content and general copyright information, consult the AMS Copyright Policy (www.ametsoc.org/PUBSReuseLicenses). 